\title{
Fire Fighting Equipment Management Based on Grid Technology
}

\author{
He Xianghui, Zhang Qingying \\ School of Logistics Engineering \\ Wuhan University of Technology \\ Wuhan, China \\ 215621539@qq.com, Kathy8899@126.com
}

\begin{abstract}
This paper put forward the new idea of combining the fire equipment with grid technology in order to improve the efficiency of the fire fighting equipment management, as well as to ensure effective supervision of fire fighting equipment.
\end{abstract}

Keywords-Fire fighting equipment; Grid technology; Resource sharing

\section{INTRODUCTION}

Fire protection is related to social stability and happiness of thousands of households. Perfection and fitness of equipment are considered as the significant foundation of fire forces to perform their functions effectively. Managing fire fighting equipment effectively is in line with the development needs of modern city and society. Applying grid technology to fire fighting equipment management is obviously helpful to improve quality control and resource sharing.

\section{THE IMPORTANCE OF FIRE FIGHTING EQUIPMENT MANAGEMENT}

Fire fighting equipment is an important tool for disaster relief and rescue. At present, the management model of fire fighting equipment still remains in the delayed examination period, which entraps manager in a passive position. Besides,during the process of managing fire fighting equipment,other problems such as insufficient care and maintenance, backward management will also seriously affect the utilization of equipment and the effect of fire rescue,and even cause a big loss of people's life and property.

\section{THE APPLICATION OF GRID TECHNOLOGY IN FIRE FIGHTING EQUIPMENT MANAGEMENT}

\section{A. Grid and Grid Technology}

Grid is a group of emerging technology which is constructed on the Internet, and it integrates high speed Internet, high performance computing, large databases, sensors, and remote equipment to provide more resources and services for scientific and technical personnel and ordinary people.

The core idea of grid technology is implementing interoperability and adequate sharing of cyber source, thereby supporting organization of daily affairs and businesses, realizing information storage, retrieval, sharing, access and other functions.
Grid technology has the characteristics of distributing, heterogeneity, scalability, adaptability and so on. Therefore grid technology has been widely applied in the area of distributed supercomputing, high throughput computing, data intensive computing, interpersonal interaction based on a wide range of shared information, as well as in the area of more extensive exchange of resources.

\section{B. Fire Equipment Management Pattern Based on Grid Technology}

Fire fighting equipment management is made up of four indispensable parts: management subject, management object, management mechanism and management target. Fire fighting management subject is the undertaker and the executor of management work, which is called fire crews. Fire fighting management object is fire fighting equipment. Fire fighting management mechanism refers to managing fire fighting equipment by using grid technology, so as to realize the target of efficient management of fire fighting equipment. The relationship between the four components of fire fighting equipment management can be described as the figure 1 .

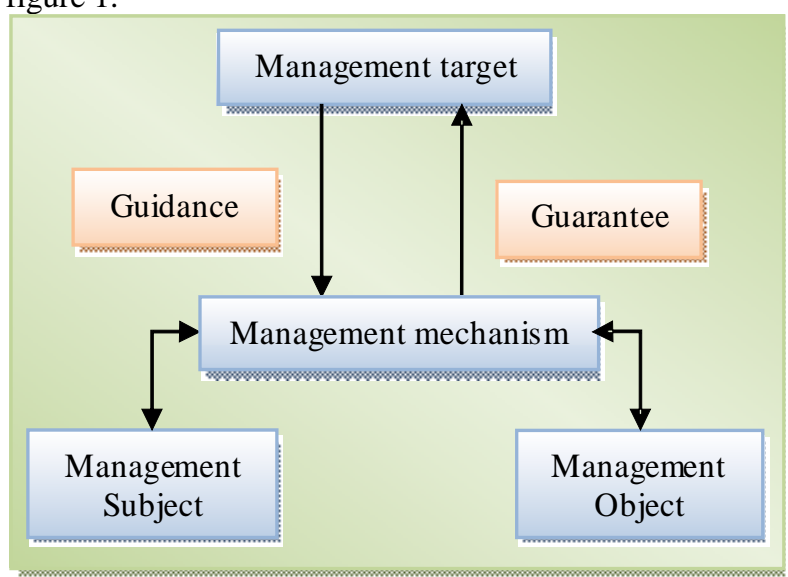

Figure 1. The relationship between four components of fire fighting equipment management

Taking information technology as the core, grid unit as the basis, fire fighting equipment management based on grid technology can realize the quantification, accuracy, initiative and real-time. It can ensure efficient management and effective supervision of fire fighting equipment. It can 
also strengthen the linkage of information sharing and resource integration between related departments, and establish two major systems of command and supervision. Through the grid management information platform, problems can be found and solved effectively. It realizes the linkage mechanism between cities, districts, professional departments and supervisors, and builds the modern fire equipment management system which caters to the development need of the oversize city.

Grid management pattern of fire equipment applies the unit grid management method, to realize the classified, hierarchical and regional management. The city can be divided into three-level grid: municipal districts are "Big Grid" which are responsible for organizing, coordinating and guiding the fire management work in the area under their jurisdiction; Street office and community are "Middle Grid" in charge of supervising, finding, disposing and verifying problems; The "Middle Grid" are divided into several responsibility areas which can be called "Small Grid". They are responsible for daily inspections and information gathering of fire fighting equipment. Take Wuchang district of Wuhan City for example, we divide the whole region into three-level grid, therefore the city will form four progressive management levels and each level has a respectively supervisor. The first level refers to the entire Wuchang district and the district government is the person liable; The second level is the 14 streets, and the subdistrict office is responsible for the management; The third level is the 191 communities, and the community residents' committee is the responsible party; The fourth level is grid unit and the responsible person is resident units. The city's grid division model is shown in figure 2 .

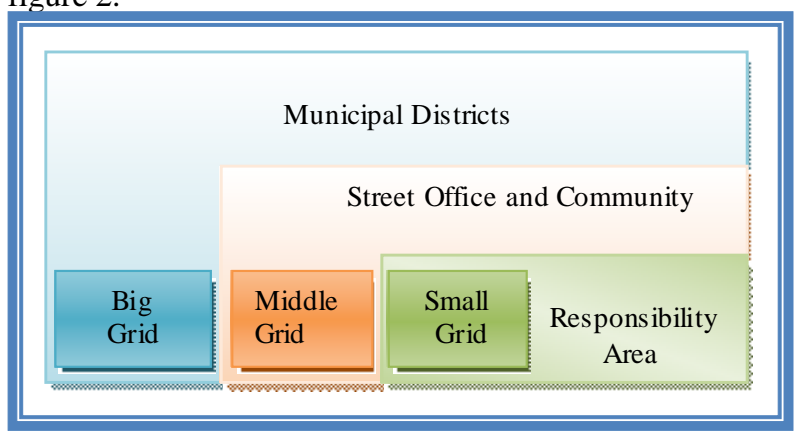

Figure 2. The city's grid division model

Geographic coding technology can make the fire unit positioned at the unit grid map according to the geographical coordinate, and then we can classify and manage the fire unit through the information platform. Each of the components is encoded, and a unified database is established. Through the information platform,you can find the exact information about the fire fighting equipment on the big screen in the supervising center and command center. Supervisors timely collect the information of fire equipment by information collector, and update the database. The general execution model of information management of fire equipment is shown in

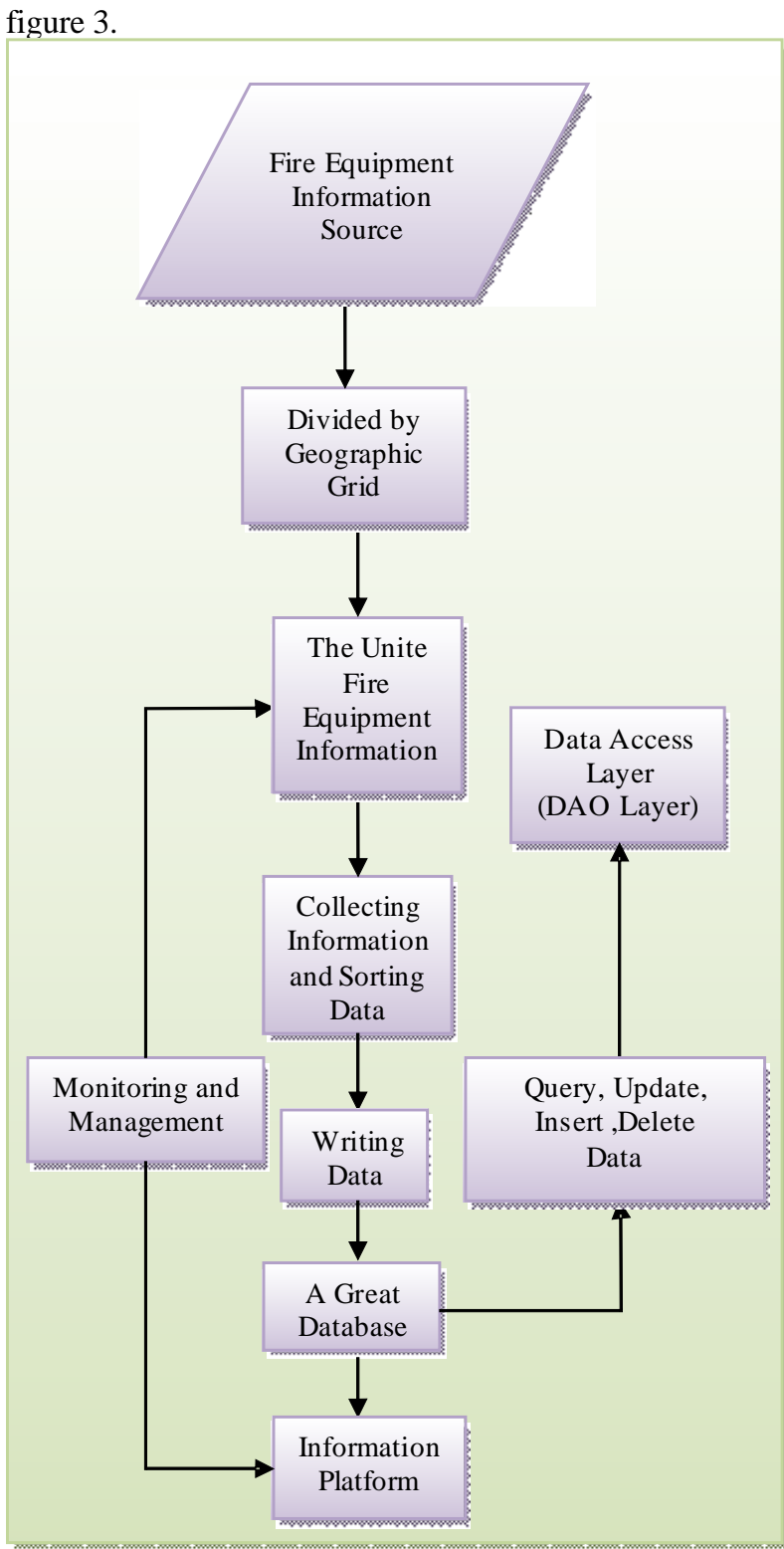

Figure 3. The general execution model of information management of fire equipment

Fire fighting equipment pattern based on grid management establishes a complete feedback control system. It can basically be summarized as six sessions:information collection, information storage, task dispatching, task processing, feedback and verification. Specific procedures are as follows: as the subject of information collection, supervisors in each grid unit will make a report to the supervision center through certain channels.At the same time, supervision center can also know the relevant issues about the public and media through hotline and website.Supervision center will store and update the information immediately after they receive it. Next,if necessary,command center will arrange people to deal with the problems.After finishing the task, 
professionals will report the handling results to the command center; Feedback results will be processed by the command center to the supervision center;As soon as supervision center receive feedback results, supervisor will verify the scene. The feedback control system of fire fighting equipment management is shown in figure 4.

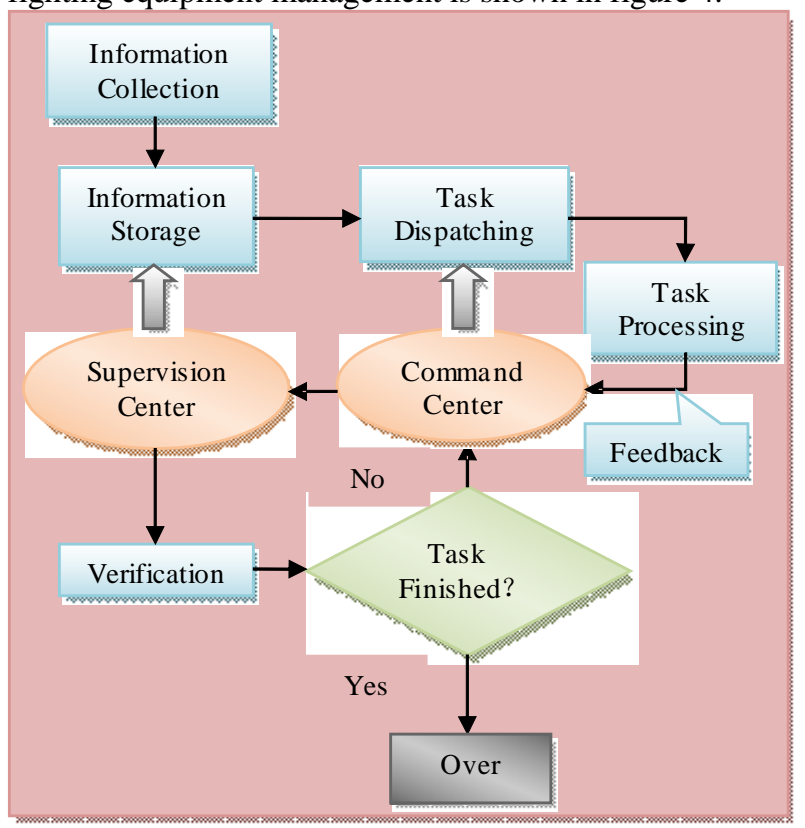

Figure 4. The feedback control system of fire fighting management

\section{RESEARCH CONTENTS OF FIRE EQUIPMENT MANAGEMENT BASED ON GRID TECHNOLOGY}

Grid management system of fire equipment is designed mainly to solve the following four contents.

\section{A. Digitized Management Objects}

The first step to construct grid management system is to divide the grid unit, therefore there must be some grid division standards, to make the construction of each grid unit standardized, and to facilitate the implementation of grid management.

- Make grid division on the management areas. The management areas are divided into unit grid according to the administrative area, and a certain number of supervisors are settled.

- Unified coding of the component and event. The fire fighting management object is uniformly shown as component and event. The name, the classification and the attribute description of facilities of fire fighting equipment must be defined clearly. The whole city develops a unified component and event database, and different district must backup their data respectively.

\section{B. Networked Information Processing}

- Field information collection. Design the mobile terminal with special software for fire protection management, and the mobile terminal is called"
XiaoFangTong" ( equipped with electronic map ), then supervisors use "ChengGuanTong" to easily collect the scene information ( pictures, text ).

- Network communication support. Supervisors and urban supervision platform are composed of data chain by renting special mobile communication line.

- Information data storage. The whole city's event database is stored in the supervision center of municipal construction commission, and each district backups its data to the district supervision center. Business processing information can be updated synchronously.

\section{Clarified Responsibility Between City and District}

- Municipal level and district level perform their functions separately. City regulatory platform: focusing on the analysis, monitoring and evaluation, responsible for forwarding the collected information to the district platform, directing and coordinating the city's professional departments, regulating and evaluating area platform. District regulatory platform: focusing on the finding, supervision, coordination, disposal, and verification of issues, and it is the operation entity of the urban grid management.

- Separating the regulatory functions. Both municipal level and district level are isolated from the urban management officers' supervision and management functions, and the monitoring center and command center are respectively set up.

\section{Standardized Work Processes}

Grid management model of fire-fighting equipment re-integrates all kinds of resources of cities, districts, streets, and professional management departments, and recycles cross-organizational business processes which is tightly linked such as finding, commanding, processing, and feeding back issues. Business processes which is based on grid management finish the complete inspection of the management area and the management objects.

\section{CONCLUSION}

Through establishing grid system and realizing the whole management process of fire fighting equipment, it's likely to ensure safe and efficient use of fire fighting equipment. If the fire fighting equipment is divided into the grid unit in accordance with certain standards, and the coordination mechanism between modern information technology and grid unit is fully utilized, then each grid unit can effectively make information exchange, transparently share resources of organization, and all of this will provide an useful way to effectively solve problems like integrative optimization, resource sharing, and efficient management of the fire fighting equipment.

\section{REFERENCES}

[1] Maozhen Li, Mark Baker, 2005, The Grid: Core Technologies[M]. John Wiley \& Sons. 
[2] Yan Xu, "Analysis of fire-fighting equipment management," [J] Pioneering with Science\& Technology Monthly, 2012,(6):105-107.

[3] Yao Sun, "Research and Implementation of Grid information management system based on WCF" [D]. Northeast Normal University,2009.
[4] Klaus Kayser, Jürgen Görtler, Torsten Goldmann, Ekkehard Vollmer, Peter Hufnagl and Gian Kayser, "Grid computing in image analysis" [J]. Diagnostic Pathology 2011, 6(Suppl 1):S12.

[5] Abdulrahman Yarali, Saifur Rahman., "Smart Grid Networks: Promises and Challenges" [J]. Journal of Communications, Vol 7, No 6 (2012), 409-417, Jun 2012. 